\title{
ANALYTIC ISOPERIMETRIC INEQUALITIES
}

\author{
Hsu-Tung Ku AND MeI-CHIN Ku
}

Abstract. In this paper we introduce the concept of area functions for a given function. We then apply these area functions to establish new analytic and geometric isoperimetric inequalities.

Mathematics subject classification (1991): 26B25, 26D20, 26D05, 51M16, 51M25.

Key words and phrases: cyclic polygon, analytic and geometric isoperimetric inequalities, Jensen's inequality, quadratic Jensen's inequality.

\section{REFERENCES}

1] G. S. Bhallla, Brahmagupta's quadrilateral, Math. Comput. Ed. 20 (1986), 191-196.

[2] J. Chevel, Eigenvalues in Riemannian Geometry, Academic Press, New York, 1984.

[3] R. Courant And D. Hilbert, Methods of Mathematical Physics, Vol. I, Interscience, New York 1953.

[4] G. Hardy, J. E. LitTlewood And G. Polya, Inequalities, Cambridge Univ. Press, Cambridge, New York 1951.

[5] A. HuRwitz, Surquelgues applications géométriques des series Fourier, Ann. Éc. Norm. 19 (1902), 357-408.

[6] M. D. KAZARINOFF, Geometric Inequalities, New Math. Library, Math. Assoc. of America, 1961.

[7] H. T. Ku, M. С. Ки and X.M. Zhang, Analytic and Geometric isoperimetric inequalities, J. Geom. 53 (1995), 100-121.

[8] H. T. KU, M.C. KU AND X. M. ZHANG, Isoperimetric inequalities on surfaces of constant curvature, Can. J. Math. 49 (1997), 1162-1187.

[9] D. S. MACNAB, Cyclic polygons and related questions, Math. Gazette 65 (1981), 22-28.

[10] R. Osserman, The isoperimetric inequality, Bull. Amer. Math. Soc. 84 (1978), 1182-1238.

[11] G. Polya And G. Szegö, Isoperimetric inequalities in Mathematical Physics, Ann. of Math., Studies No. 27, Princeton Univ., Princeton, 1951.

[12] D. P. RobBIns, Areas of polygons inscribed in a circle, Discrete Comput. Geom. 12 (1994), $223-236$.

[13] A. W. Robert And D. E. VARBERG, Convex Functions, Academic Press, New York, San Francisco, London, 1973.

[14] R. SCHEOn AND S.T. YAN, Differential Geometry, Beijing, China, 1988.

[15] B. Su, Lectures on Differential Geometry, World Scientific, Singapore, 1980.

[16] D. Tang, Discrete Wirtinger and isoperimetric inequalities, Austral. Math. Soc. 43 (1991), 467-474.

[17] X. M. ZHANG, Bonnesen-style inequalities and pseudo-perimeters for polygons, J. Geom. 60 (1997), 188-201.

[18] X. M. ZHANG, Schur-convex functions and isoperimetric inequalities, Proc. Amer. Math. Soc. 26 (1998), $461-470$.

[19] X. M. ZHANG, Optimization of Schur convex functions, Math. Inequalities \& Appl. 1 (1998), 319-330. 